\title{
Notice on a methodology for characterizing emissions of ultrafine particles/nanoparticles in microenvironments
}

This article was published in the following Dove Press journal:

Energy and Emission Control Technologies

6 November 2013

Number of times this article has been viewed

\author{
João Fernando Pereira \\ Gomes ${ }^{1,2}$ \\ Paula Cristina Silva \\ Albuquerque $^{3}$ \\ Helder Manuel Dias \\ Salvação Esteves ${ }^{4}$ \\ Patrícia Almeida Carvalho ${ }^{5}$ \\ 'Chemical Engineering Department, \\ ISEL, Lisbon Polytechnic, R. Conselheiro \\ Emidio Navarro, Lisbon; ${ }^{2}$ IBB - Institute \\ of Biotechnoloy and Bioengineering, \\ IST, Technical University of Lisbon, \\ Lisbon; ${ }^{3}$ ESTESL - School of Health \\ Tecnologies, Lisbon Polytechnic, Lisbon; \\ ${ }^{4}$ Bioengineering Department, IST, \\ Technical University of Lisbon, Lisbon; \\ ${ }^{5}$ InAir, Lda., Moita, Portugal
}

Correspondence: João Fernando Pereira Gomes

Instituto Superior de Engenharia de Lisboa, Área Departamental de Engenharia Química,

R Conselheiro Emídio Navarro, 1959-007 Lisboa, Portugal

Tel +351218317000

Fax +351218317001

Email jgomes@deq.isel.ipl.pt

\begin{abstract}
Bearing in mind the potential adverse health effects of ultrafine particles, it is of paramount importance to perform effective monitoring of nanosized particles in several microenvironments, which may include ambient air, indoor air, and also occupational environments. In fact, effective and accurate monitoring is the first step to obtaining a set of data that could be used further on to perform subsequent evaluations such as risk assessment and epidemiologic studies, thus proposing good working practices such as containment measures in order to reduce occupational exposure. This paper presents a useful methodology for monitoring ultrafine particles/ nanoparticles in several microenvironments, using online analyzers and also sampling systems that allow further characterization on collected nanoparticles. This methodology was validated in three case studies presented in the paper, which assess monitoring of nanosized particles in the outdoor atmosphere, during cooking operations, and in a welding workshop.
\end{abstract}

Keywords: ultrafine particles, exposure assessment, monitoring methodology

\section{Introduction}

The influence of very ultrafine particulates (UFPs), lying in the nano range, on human health has already been reported to be of much concern. ${ }^{1}$ In fact, airborne nanoparticles can result both from nanotechnology processes and from macroscopic common industrial processes such as granulated materials handling and metals processing.

Currently, nanotoxicology research is still in its infancy, and the issuing and implementation of standards for appropriate safety control systems can still take several years. However, the advanced understanding of toxicological phenomena on the nanometer scale is largely dependent on technological innovations and scientific results stemming from enhanced research and development. Meanwhile, the industry has to adopt proactive risk management strategies in order to provide a safe working environment for staff, clients, and customers, and also to obtain products representing no health threats at any point of their life cycle.

Nanoparticle materials can enter the body via three main routes: (1) inhalation, (2) ingestion, and (3) dermal penetration. The detrimental health effects of inhaling fine aerosols were recognized long ago, ${ }^{1}$ and various attempts have been made to minimize exposure, such as the issuing of specific regulations on emissions and objectives for air quality and workplace atmosphere. Although toxicological tests of nanoparticles entering through the skin or the gastrointestinal tract are still being performed, inhalation technology has been concerned with both naturally occurring and engineered nanometer-sized materials for some time. ${ }^{2}$ Most studies, however, have resulted in contradictory and controversial conclusions, and little or no standardization of experimental parameters 
has been derived thereafter. In particular, standard toxicology tests have been found to be unsuitable to explain the high toxicity of nanometer-sized particles, leading nanotoxicology laboratories to recommend the adoption of another type of metrics that takes into account the material's active surface area and structure. Therefore, recent nanotoxicology studies are trying to reach reproducible results by determining the surface effects and other physical parameters of the materials. This question is particularly important, namely for the European chemical industry, due to the adoption of Registration, Evaluation, Authorisation and Restriction of Chemicals (REACH) regulations, and it has been recommended that nanoparticulate materials are to be treated as new substances under the REACH regulation, which will supersede the existing notification of new substances.

Previous studies ${ }^{2,3}$ have shown the dominant role of indoor air in personal exposure to many air pollutants. These findings are explained by the high proportion of time that people spend indoors and by the high concentrations of many air pollutants found there. The main issue in designing exposure assessment studies is which of the microenvironments where people spend their time should be the one studied in order to provide reliable data allowing for most accurate assessments, simultaneously limiting the costs and work efforts in performing those studies.

When considering human exposure to airborne pollutants, of particular importance is exposure to airborne particles, specifically to their finer fractions: nanoparticles, UFPs, submicrometer particles, and $\mathrm{PM}_{2.5}$ (particles with size lower than 2.5 $\mu \mathrm{m})$ and $\mathrm{PM}_{10}$ (particles with size lower than $10 \mu \mathrm{m}$ ) fractions. Obviously, the smaller the particles the higher the probability of penetration into deeper parts of the respiratory tract, and also that they contain higher levels of trace elements, toxins, and mutagens. It should be noted that in air media, smaller and larger particles behave differently, and the penetration of particles of different sizes through the building envelope is different. Theoretically, the indoor particle concentration is a function of a number of factors, such as generation rate of particles indoors, outdoor particle concentration, air exchange rate, particle penetration efficiency from the outdoor to the indoor environment, and the particle deposition rate on indoor surfaces. ${ }^{3}$ However, in practice, it is usually very difficult to assess the exposure, due to the lack of data and information on the correlation between indoor and outdoor particles, which are building and environment specific.

Understanding the relationship of indoor and outdoor aerosol particles, especially in the nano range, under different environmental conditions is of major importance for improving exposure estimates and for developing efficient control strategies to reduce human exposure and thus health risk. ${ }^{4}$ Current exposure assessment models are often based on the outdoor pollutant concentration used as input parameter for predicting total exposure. However, the indoor concentrations may be different from the outdoor ones, even in the absence of any significant indoor pollution sources. This is particularly true when the nano range of particulate is considered. Understanding the relationship of airborne nanosized particulate and human health under different environmental conditions is of great importance for improving exposure estimates and for developing efficient control strategies to reduce human exposure and health risk and for establishing, evaluating, and improving regulations and legislation on air quality, airborne emissions, and the incorporation of nanosized materials in other products and commodities.

\section{Exposure assessment}

At this time, occupational health risks associated with the manufacturing and use of nanoparticles are not yet clearly and fully understood. However, workers may be exposed to nanoparticles through inhalation at levels that can greatly exceed ambient concentrations. ${ }^{5}$

Current workplace exposure limits that were established long ago are based on particle mass criteria. However, this criterion does not seem adequate in what concerns nanoparticles. Nanoparticles are, in fact, characterized by very large surface areas, which are the distinctive characteristic that could even turn an inert substance into another substance with the same chemical composition but exhibiting very different interactions with biological fluids and cells. ${ }^{3}$ Of course, these interactions may become beneficial. Therefore, it seems that assessing human exposure based only on the mass concentration of particles, which is widely adopted for particles over $1 \mu \mathrm{m}$, may not be adequate for this particular case. As a matter of fact, nanoparticles have far more surface area for their equivalent mass of larger particles, which increases the chance that they may react with body tissues. ${ }^{4}$ Thus, a growing number of experts ${ }^{7,8}$ have been claiming that surface area should be used instead for nanoparticle exposure and dosing. As a result, assessing workplace conditions and personal exposure based on the measurement of particle surface area is becoming of increasing interest.

It is well known that lung deposition is the most efficient way that airborne particles can enter the body and potentially cause adverse health effects. Properties that contribute to the toxic effects of nanoparticles include ${ }^{3,7}$ solubility, particle 
morphology, particle size, composition, surface chemistry, surface coatings, and surface area. If nanoparticles can deposit in the lung and remain there, have an active surface chemistry, and interact with the body, then there is some potential for exposure and dosing. Oberdörster ${ }^{9}$ showed that surface area plays an important role in the toxicity of nanoparticles, and this is the measurement metric that best correlates with particle-induced adverse health effects. The potential for adverse health effects seems to be directly proportional to particle surface area. ${ }^{10}$

\section{Nanoparticle surface area measurement}

Mass measurement methods are not sufficiently sensitive for airborne nanoparticles and thus are not sensitive toward the specific health-relevant properties of nanoparticles. ${ }^{11}$ The most sensitive concentration measured in this particle range $(<100 \mathrm{~nm}$ diameter) is the number concentration. However, the number concentration is dominated by very small particles, which are difficult to measure because of increasing line losses and decreasing counting efficiency observed for all particle counters when a size decrease occurs. ${ }^{9}$ Apart from that, it is doubtful whether the number concentration can be well correlated with predominant health effects. This seems to be true for asbestos fibers, in which fibers have a certain probability to cause a negative health effect, and may also be true for nanoparticles in case of clogging after penetrating into the blood. ${ }^{7,8}$ As pointed out by Oberdörster, ${ }^{7}$ surface area is a relevant metric for nanoparticles, as most of the processes in the human body environment take place via the particle surface, which is increasing significantly when particle size significantly decreases. This takes place in the nanometer size range for the same amount of particle mass. Thus, the health effects after intake are strongly dependent also on the deposition regions. The deposition in the nose (head) is particularly discussed because of the possible transfer of nanoparticles to the brain, as well as the tracheobronchial (TB) and alveolar regions, because of the inefficiency of the clearing mechanism and the possible transfer to the blood circulation system, which, ultimately, will result in its distribution between several end organs. ${ }^{6}$

Figure 1 shows the various regions of the human lung, which forms the basis of the model used by the International Commission on Radiological Protection (ICRP) and the US Environmental Protection Agency to define and characterize human lung deposition. In 1996, the ICRP developed a comprehensive lung deposition model for radioactive aerosols. ${ }^{12}$

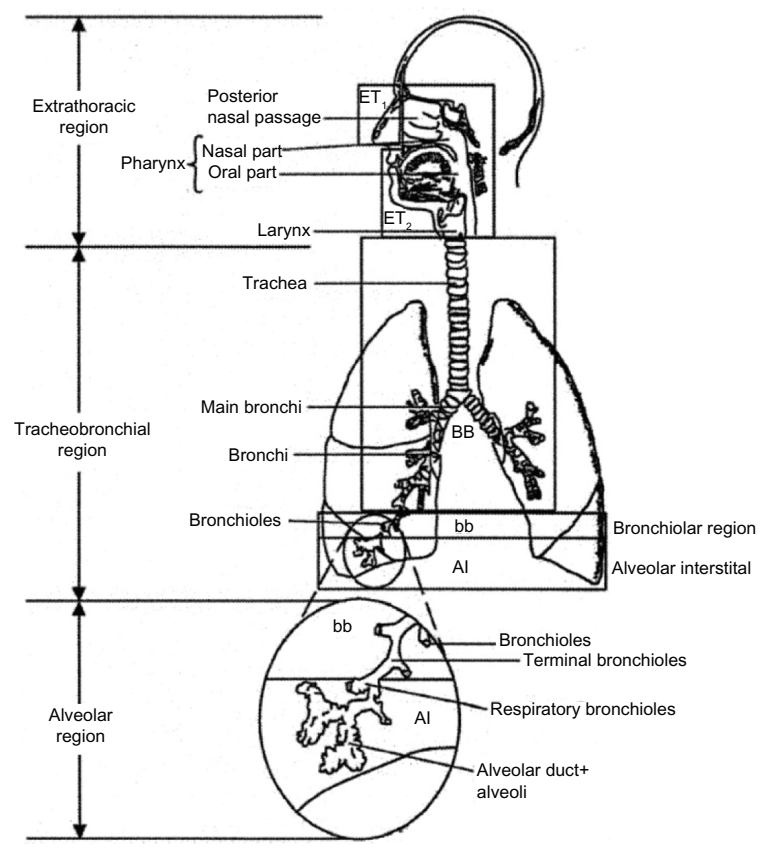

Figure I Schematic of human lung regions. ${ }^{12}$

Abbreviations: ET, extrathoracic; BB, bronchi; bb, bronchioles; Al, alveoli. Reproduced with permission from TSI Incorporated.

Several parameters are required to construct the model, including breathing rate, lung volume, activity, and nose/ mouth breathing.

The obtained deposition curves (for TB and alveolar deposition) derived from the model can vary according to these parameters. For industrial hygiene applications, the American Conference of Governmental Industrial Hygienists $(\mathrm{ACGIH})^{12}$ developed a definition of a reference worker, as presented in Table 1, in order to derive the respective deposition curves as referred to in Table 1.

Table I Parameters characterizing a reference worker, according to the American Conference of Governmental Industrial Hygienists

\begin{tabular}{|c|c|c|}
\hline \multicolumn{3}{|c|}{ Type of parameter } \\
\hline Physiological & Activity related & Aerosol \\
\hline Subject: adult male & $\begin{array}{l}\text { Activity type: nose } \\
\text { breathing only }\end{array}$ & $\begin{array}{l}\text { Activity mean } \\
\text { aerodynamic diameter: } \\
0.001-0.5 \mu \mathrm{m}\end{array}$ \\
\hline $\begin{array}{l}\text { Functional residual } \\
\text { capacity: } 2,200 \mathrm{~cm}^{3}\end{array}$ & $\begin{array}{l}\text { Ventilation rate: } \\
1.3 \mathrm{~m}^{3} / \mathrm{hr}\end{array}$ & $\begin{array}{l}\text { Geometric standard } \\
\text { deviation: } 1.0\end{array}$ \\
\hline $\begin{array}{l}\text { Extrathoracic dead } \\
\text { space: } 50 \mathrm{~cm}^{3}\end{array}$ & $\begin{array}{l}\text { Respiratory frequency: } \\
\text { I5.0 breaths/min }\end{array}$ & Density: $1.0 \mathrm{~g} / \mathrm{cm}^{3}$ \\
\hline $\begin{array}{l}\text { Bronchiolar dead } \\
\text { space: } 47 \mathrm{~cm}^{3}\end{array}$ & Tidal volume: $1450 \mathrm{~cm}^{3}$ & Shape factor: 1.0 \\
\hline Height: 175 cm & $\begin{array}{l}\text { Volumetric flow rate: } \\
725 \mathrm{~cm}^{3} / \mathrm{s}\end{array}$ & \\
\hline $\begin{array}{l}\text { Tracheal diameter: } \\
1.65 \mathrm{~cm}\end{array}$ & $\begin{array}{l}\text { Fraction breathed } \\
\text { through nose: } 1.0\end{array}$ & \\
\hline $\begin{array}{l}\text { First bronchial } \\
\text { diameter: } 0.165 \mathrm{~cm}\end{array}$ & & \\
\hline
\end{tabular}


The obtained curves for TB and alveolar lung deposition, based on the reference worker parameters and the ICRP model, are presented in Figure 2. The TB deposition curve represents the fraction of aerosol that deposits in the TB region of the lung, and the alveolar deposition curve represents the fraction of the aerosol that deposits in the alveolar region of the lung. For exposure assessment applications, it is common to sample aerosols relevant to their deposition in a specific region of the human lung, which is often referred to as size-selective health hazard sampling. The criterion for size-selective sampling depends on the aerosol being sampled. Thus, as for nanoparticles, the resulting health effects are mainly related to the deposition deep in the alveolar regions of the lung. The respirable fraction of the aerosol seems to be the metric of interest.

\section{Description of the methodology for exposure assessment}

The proposed methodology, which comes in line with recently defined strategies for measurement of airborne nanomaterials, ${ }^{13}$ is mainly based on the estimation of the area of UFPs deposited in the alveolar tract of the human lung, using the ICRP model. ${ }^{12}$ However, as this is, in fact, an estimate and not an actual direct measurement using equipment such as a nanoparticle surface area monitor (NSAM), these observations are to be confirmed by other less "indirect" measurements. In the proposed methodology, we complement the previous tests by measuring size distribution and morphology, and chemical analysis as well. Therefore, the proposed methodology comprises the subsequent steps.

1. Alveolar (or TB)-deposited surface areas of emitted nanoparticles are monitored online using an NSAM analyzer, which allows the estimation of the quantity of nanoparticles, expressed as $\mu \mathrm{m}^{2} / \mathrm{cm}^{3}$, during the respective release period. If adequate software is used for data acquisition, the emissions could even be ascribed to specific process events.

2. The size range distribution of released nanoparticles is measured online using a monitor such as a scanning mobility particle sizer spectrometer (SMPS).

3. Released nanoparticles are simultaneously sampled with a sampler such as a nanometer aerosol sampler for further observation and characterization. Nanoparticles are to be collected in a suitable substrate, such as copper or nickel grids. It should be noted that sampling should be performed during a sufficient time span in order to capture enough nanoparticles for observation and analysis.

4. Finally, the previously collected sample can be observed using electron microscopy, which allows the determination of morphology, dimensions, crystalline structure, and even chemical composition. A suitable alternative is to use scanning transmission electron microscopy (TEM) apparatus, coupled with an electron dispersive X-ray spectroscopy, which will be described hereafter in this paper.

This methodology has been tested in some case studies, which are described elsewhere relating to ambient air, ${ }^{14}$ indoor environments, ${ }^{15,16}$ and also occupational welding environments. ${ }^{17}$

\section{Materials and methods Nanoparticle surface area monitoring}

For measuring nanoparticle exposure, an NSAM (TSI Incorporated, Shoreview, MN, USA), Model 3550, was used.

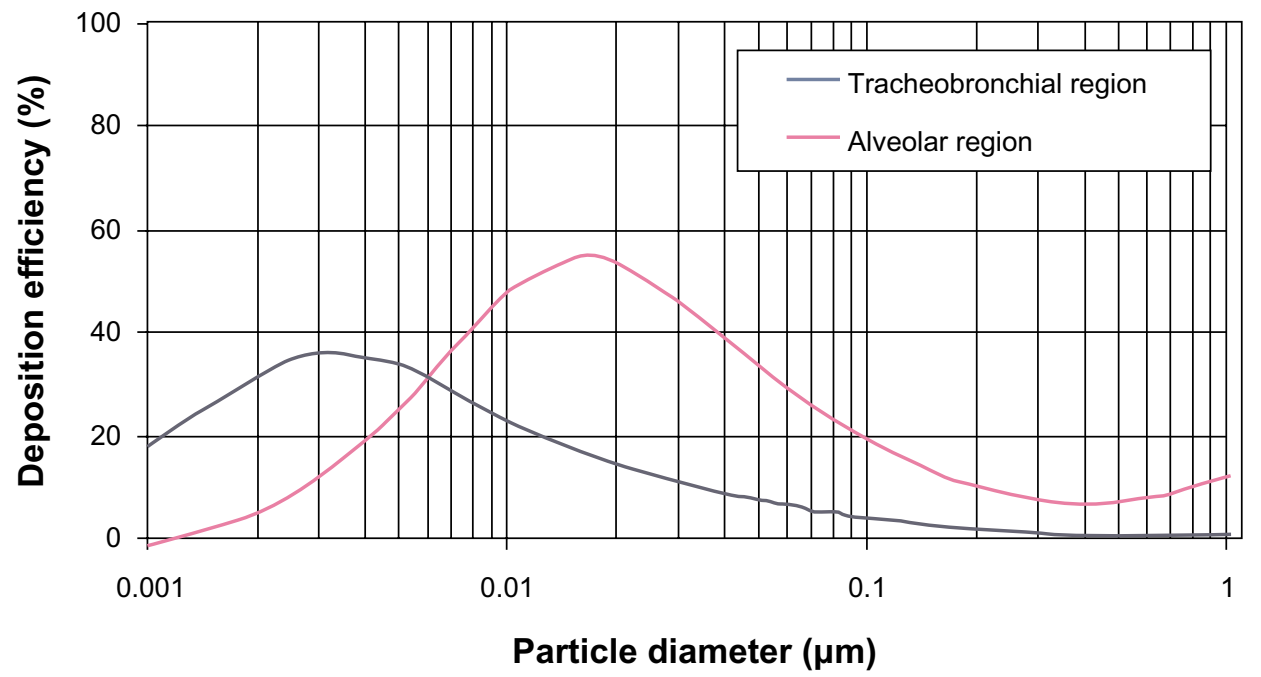

Figure 2 Deposition curves for particles in tracheobronchial and alveolar regions of the lung. ${ }^{8}$ Reproduced with permission from TSI Incorporated. 
This equipment indicates the human lung-deposited surface area of particles expressed as square micrometers per cubic centimeter of air $\left(\mu \mathrm{m}^{2} / \mathrm{cm}^{3}\right)$, corresponding to TB and alveolar regions of the lung. This equipment is based on diffusion charging of sampled particles, followed by detection of the charged aerosol using an electrometer. Using an integral pump, an aerosol sample is drawn into the instrument through a cyclone with a $1 \mu \mathrm{m}$ cut point. The sample flow is split, with one stream going through a set of carbon and high-efficiency particulate air filters and an ionizer to introduce positively charged ions into a mixing chamber. The other aerosol flow stream is mixed with the ionized stream in a mixing chamber, and charged aerosol and excess ions move on to an ion trap. The ion trap voltage can be set to TB or alveolar response. The ion trap acts as an inlet conditioner or a size-selective sampler for the electrometer, by collecting the excess ions and particles that are not of a charged state, corresponding to the TB or alveolar response settings. The aerosol then moves on to the electrometer for charge measurement, where current is passed from the particles to a conductive filter and measured by a

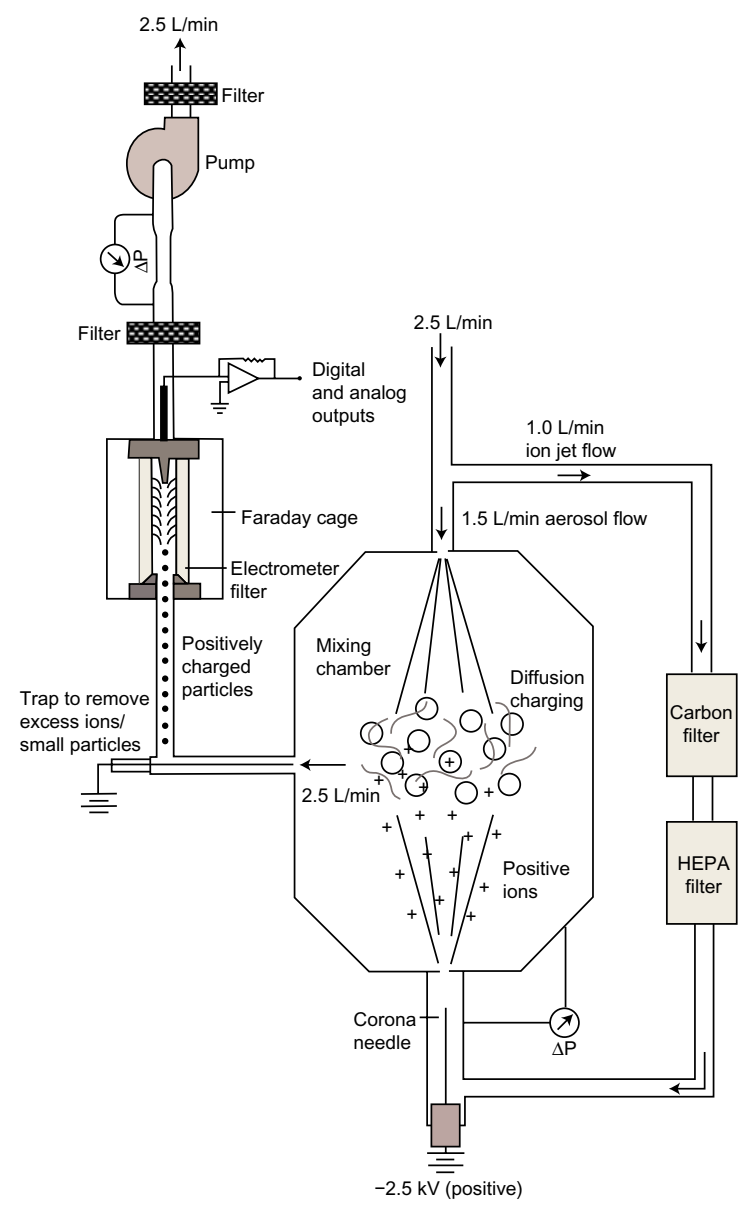

Figure 3 Schematic of the nanoparticle surface area monitor operation. Abbreviations: HEPA, high-efficiency particulate air; $\triangle \mathrm{P}$, differential pressure. very sensitive amplifier, as shown schematically in Figure 3. The charge measured by the electrometer is directly proportional to the surface area of the particles passing through the electrometer. The equipment, when set to TB or alveolar response settings, matches the corresponding lung deposition criteria of particles for a reference worker predicted by human lung deposition models from ICRP and ACGIH.

Other alternative monitoring equipment includes (1) online, such as portable aerosol photometers and condensation particle counters, and (2) offline, such as impact aerosol separators, which require further analysis, as discussed elsewhere. ${ }^{13,18}$ The precision of this equipment has been estimated at $10 \% .^{13}$

\section{Size distribution monitoring}

Particle number concentration and size distribution were measured using an SMPS (TSI Incorporated), Model 3034. The system consists of three components: (1) a bipolar radioactive charger for charging the particles, (2) a differential mobility analyzer for classifying particles by electrical mobility, and (3) a condensation particle counter for detecting particles. The SMPS measures the particle diameter (Dp) (in terms of electrical mobility diameter) between $10 \mathrm{~nm}$ and $487 \mathrm{~nm}$ using 54 size channels (32 channels per decade) for number concentrations in the range from $102 \# / \mathrm{cm}^{3}$ to $107 \mathrm{\#} / \mathrm{cm}^{3}$. The detection method uses an optical technology that magnifies the UFPs when condensing in n-butanol. Particles are then separated by means of a differential mobility size analyzer, which selects them through their electrical charge distribution. The number of particles is determined using a counter of condensed particles through a laser beam and a photodetector. As referenced by Ostraat et al, ${ }^{13}$ the maturity of this technology has permitted its application in a variety of scenarios, both for occupational atmospheres and for indoor air environments. The precision of this equipment has been estimated at $3 \%-3.5 \% .^{13}$

\section{Sampling of UFPs}

Particles were also collected using a nanometer aerosol sampler (TSI Incorporated), Model 3089, on 3 mm diameter copper grids, polymer coated for further observation. This sampler, apart from a pump, uses an electrometer for charging nanoparticles and collecting them, as depicted in Figure 4.

\section{Observation, morphology, and composition}

Nanoparticles collected by a nanometer aerosol sampler on $3 \mathrm{~mm}$ diameter copper grids (Ted Pella Inc, Redding, CA, USA) 


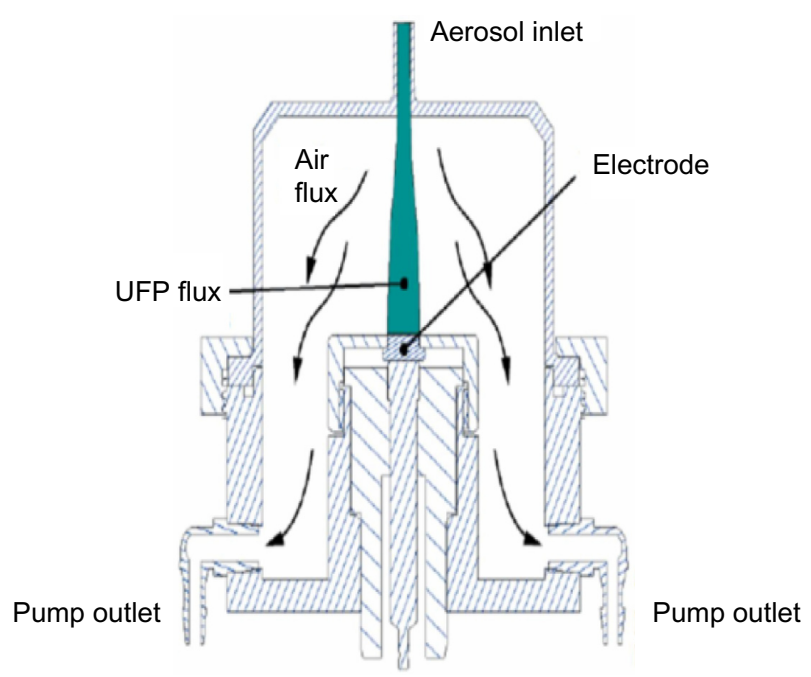

Figure 4 Schematic of the nanometer aerosol sampler operation. Abbreviation: UFP, ultrafine particle.

are bound to be further observed by electron microscopy. It was found that TEM is the most useful technique. ${ }^{19}$ In the performed studies, ${ }^{14-17}$ a TEM (Hitachi, Ltd, Tokyo, Japan), Model H-8100 II, equipped with an energy dispersive X-ray spectroscopy probe, was used. This allows the precise observation of the nanoparticles in terms of size, morphology, aggregation, crystalline forms, and also elementary chemical analysis. Other specific X-ray probes allow the determination of the molecular composition of the particles.

\section{Results and discussion \\ Case study I: determination of UFPs in the urban outdoor atmosphere of Lisbon, Portugal}

The aim of this study was the assessment of exposure to UFPs in the urban environment of Lisbon, Portugal, due to automobile traffic, and consisted of the determination of alveolar-deposited surface area (ADSA) in an avenue leading to the town center during late spring. ${ }^{14}$ This study revealed differentiated patterns for week days and weekends, which could be related with the fluxes of automobile traffic. During a typical week, UFPs deposited on alveolar surface area varied between $35.0 \mu \mathrm{m}^{2} / \mathrm{cm}^{3}$ and $89.2 \mu \mathrm{m}^{2} / \mathrm{cm}^{3}$, which is comparable with levels reported for other towns such as in Germany ${ }^{18}$ and the United States. ${ }^{19}$ These measurements were also complemented by measuring the electrical mobility diameter and number of particles, which showed values higher than those previously reported for Madrid ${ }^{22}$ and Brisbane. ${ }^{23}$ Also, electronic microscopy showed that collected particles were composed of carbonaceous agglomerates, typical of particles emitted by the exhaustion of diesel vehicles. Figure 5 shows the variation of deposited surface area of UFPs with time, during 2 consecutive week days, and Figure 6 shows the superimposed measurements for 3 week days, which clearly demonstrates the existence of a pattern for week days, which is different from weekend days.

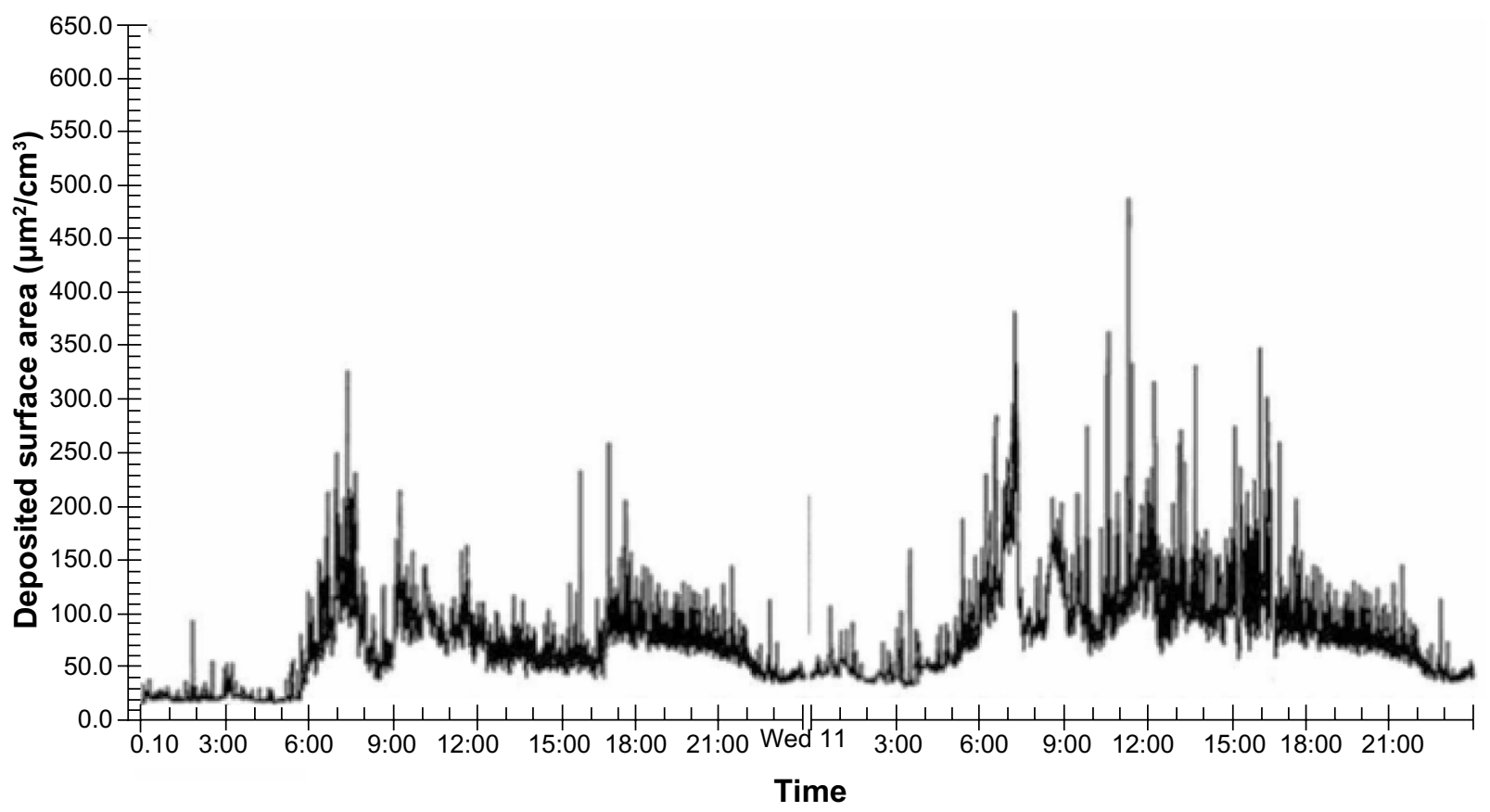

Figure 5 Measurements over 2 consecutive typical week days: Tuesday, May 10, 20II and Wednesday, May II, 20 II. 


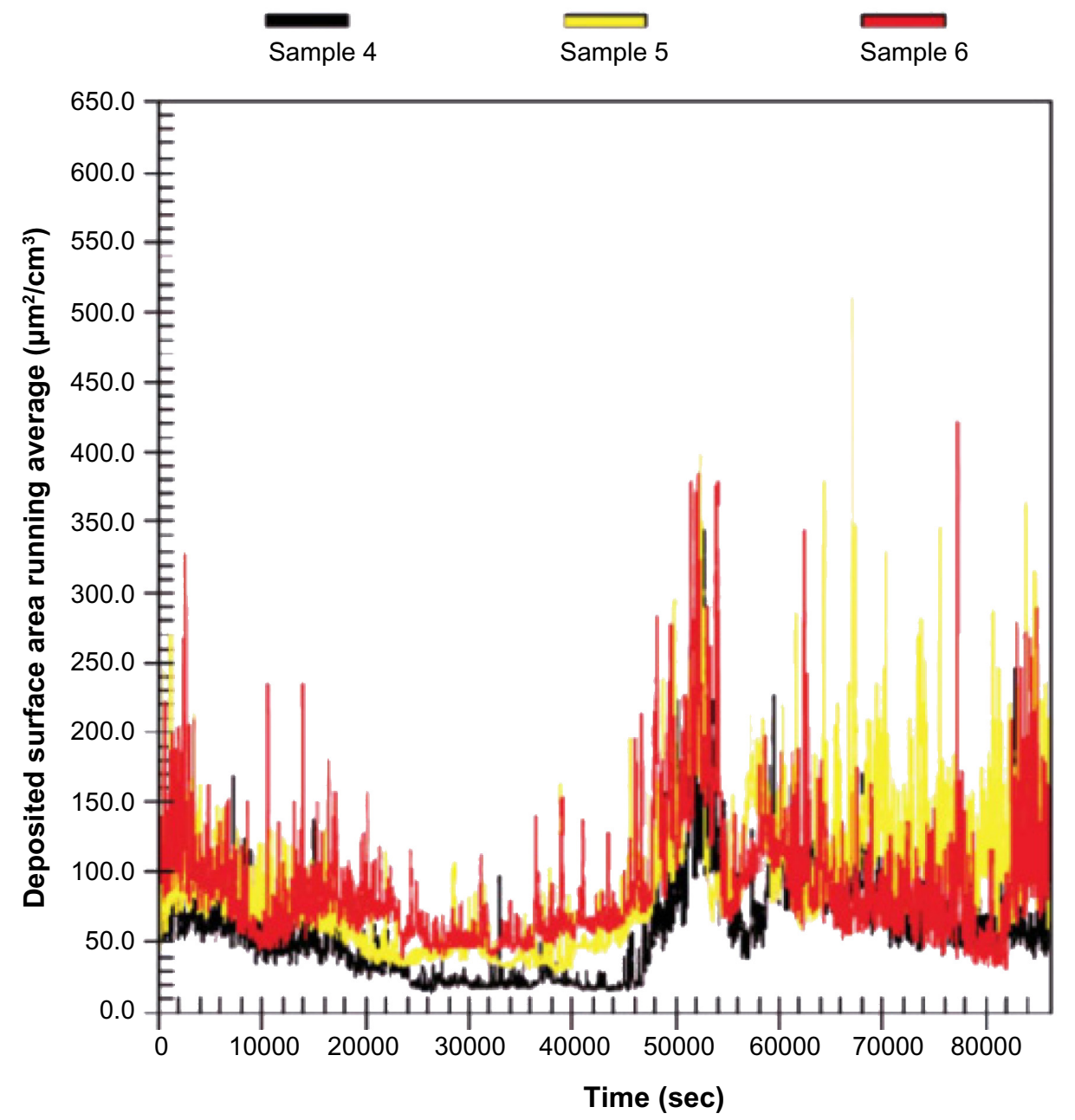

Figure 6 Superimposed measurements for 3 week days.

During week days, observed measurement peaks are due to the accumulation of heavy traffic during rush hours, which is not observed during weekends. Figure 7 shows the TEM picture of the collected UFPs on a week day, consisting mainly of agglomerates of carbonaceous particles due to

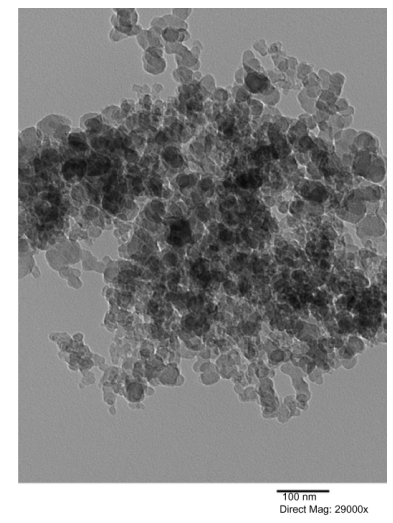

Figure 7 Transmission electron microscopy image of ultrafine particulates collected on Tuesday, May 10, 2011. the exhaustion of diesel engines, with dimensions ranging from $10 \mathrm{~nm}$ to $40 \mathrm{~nm}$, as shown in Figure 8.

\section{Case study 2: determination of UFPs from welding operations}

This study ${ }^{17}$ confirmed the emission of UFPs in the metal active gas (MAG) welding of carbon steel using mixtures of $\mathrm{Ar}+\mathrm{CO}_{2}$, which is clearly dependent on the distance to the welding front and also on the main welding parameters, namely the current intensity and heat input to the welding process. The emission of airborne UFPs increases with the current intensity, as does the fume formation rate. When comparing the tested gas mixtures, higher emissions are observed for more oxidant mixtures, ie, mixtures with higher $\mathrm{CO}_{2}$ content, which result in higher arc stability. The later mixtures originate higher concentrations of UFPs (as measured by the number of particles by $\mathrm{cm}^{3}$ of air) and higher values of the deposited surface area of particles, thus resulting in a more hazardous condition regarding workers' 


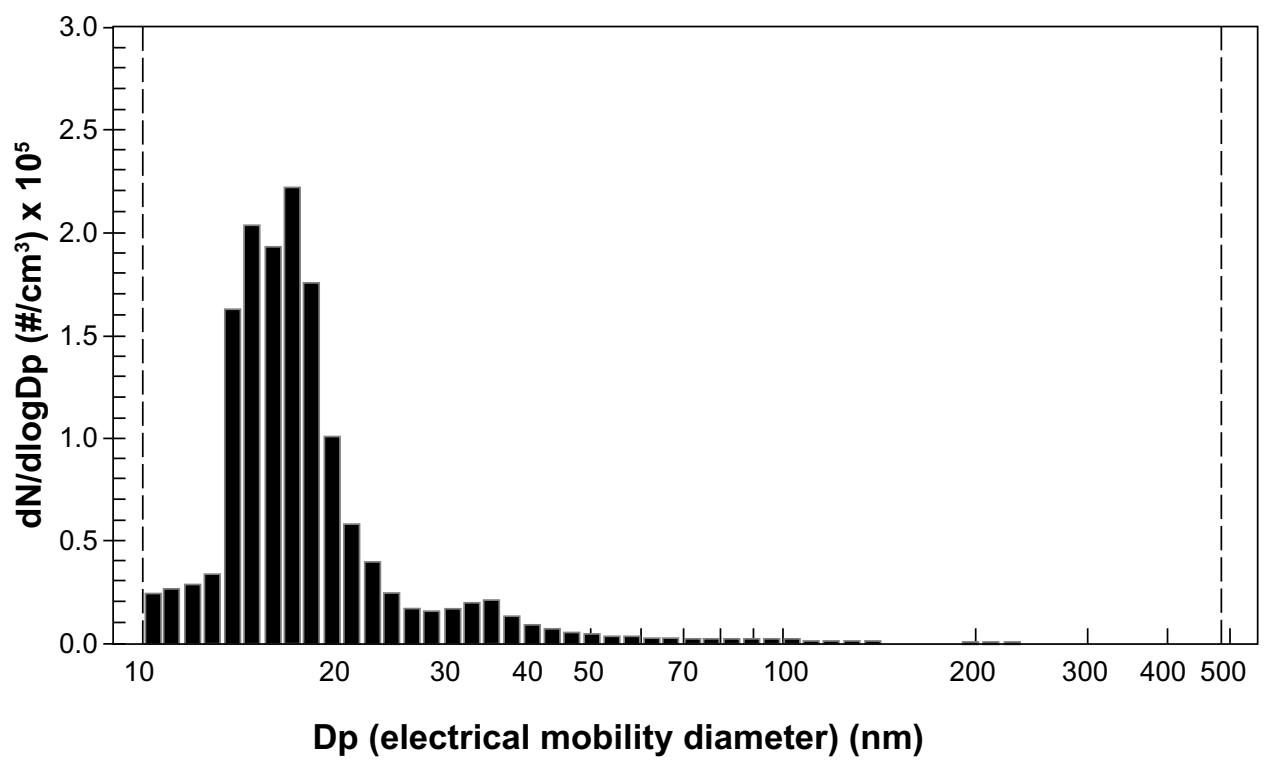

Figure 8 Size distribution of particles during a typical week day: Tuesday, May 10, 201 I.

exposure, which is in accordance with previous studies on the subject. ${ }^{24}$ Figure 9 shows the evolution of the deposited surface area of particles emitted during welding for several sampling positions at different distances from the welding front, and Figure 10 shows the measured number of particles and respective size distributions for three different operating conditions: (1) MAG welding, globular transfer mode, and using a gas protection mixture of $\mathrm{Ar}+18 \% \mathrm{CO}_{2}$; (2) same conditions but with a gas mixture of $\mathrm{Ar}+8 \% \mathrm{CO}_{2}$; and (3) MAG welding spray transfer mode and using a gas protection mixture of $\mathrm{Ar}+18 \% \mathrm{CO}_{2}$.

The morphology of sampled UFPs is shown in Figure 11, and its elementary chemical composition is shown in Figure 12.

This methodology produced results comparable with previous performed studies ${ }^{19,25,26}$ on the same subject.

\section{Case study 3: determination of UFPs from cooking operations}

Using this methodology, domestic cooking was found to be a main source of ultrafine aerosols from gas combustion in stoves and from boiling fish, boiling vegetables, frying hamburgers, and frying eggs. ${ }^{16}$ The measured ADSA of the UFPs during the cooking events significantly increased from a baseline of $72.9 \mu \mathrm{m}^{2} / \mathrm{cm}^{3}$ to a maximum of $890.3 \mu \mathrm{m}^{2} / \mathrm{cm}^{3}$ measured during fish boiling in water, and up to $4,500 \mu \mathrm{m}^{2} / \mathrm{cm}^{3}$ during frying of meat. The values measured during the tested cooking events are also significantly higher than the maximum outdoor levels measured in other major towns, ranging from $50 \mu \mathrm{m}^{2} / \mathrm{cm}^{3}$ to $70 \mu \mathrm{m}^{2} / \mathrm{cm}^{3}$. This clearly shows that a domestic activity such as cooking can lead to exposures higher than those derived from automobile traffic in a major European town. Also, significantly high values of

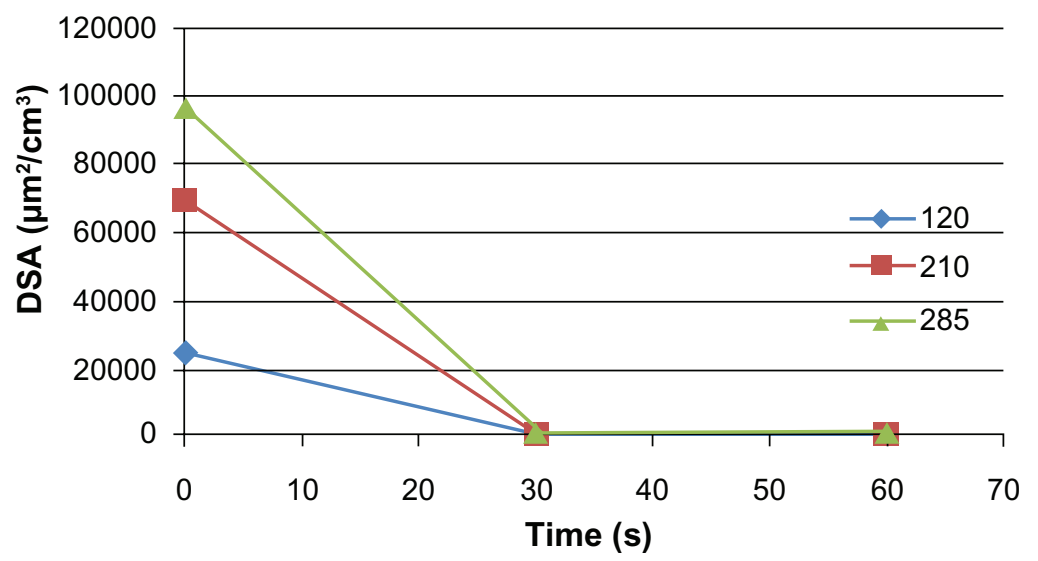

Figure 9 Plot of deposited surface area (DSA) versus time, for point $\mathrm{I}=\mathrm{I} 20$; point $2=2 \mathrm{I} 0$; point $3=285$; for globular transfer mode, at different current intensities: I20A, 210A, and 285A 
total deposited area $\left(4.72 \times 10^{7} \mu \mathrm{m}^{2}\right)$ and dose per lung area $\left(5.90 \times 10^{5} \mu \mathrm{m}^{2} / \mathrm{m}^{2}\right)$ were determined during the preparation of a whole meal composed of two dishes.

Figure 13 shows the evolution of measured ADSA during meat and egg frying.

Some authors performed studies on the emissions resulting from cooking operations, which were mainly focused on the nature of organic compounds emitted from frying meat and charbroiling in outdoor appliances. ${ }^{27,28}$ Only Hildemann et $\mathrm{a}^{29}$ and Rogge et $\mathrm{a}^{30}$ measured the size distribution of particles emitted during meat cooking, which was found to be in the range of $0.2-1 \mu \mathrm{m}$.

It should be noted that although measured parameters such as the ADSA and the dose per lung area are elevated when compared with baseline values, they cannot, at this stage, be ascertained as toxicity indicators. Nevertheless, they

A

\section{Condition 1}

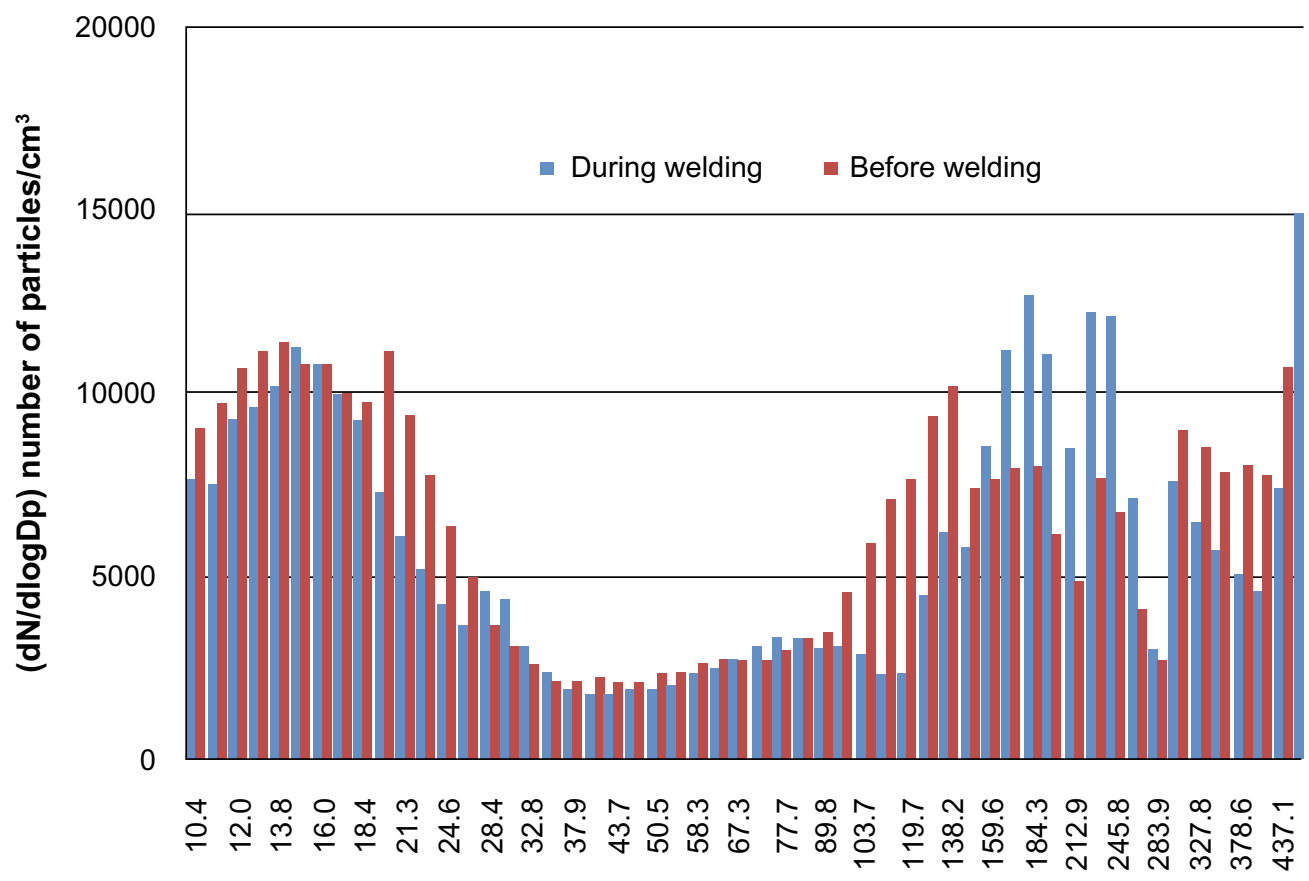

$\mathrm{Dp}(\mathrm{nm})$

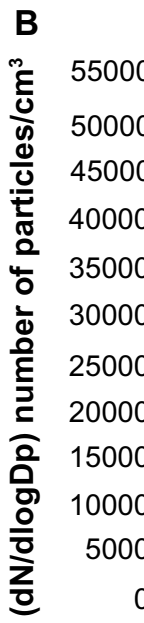

Condition 2

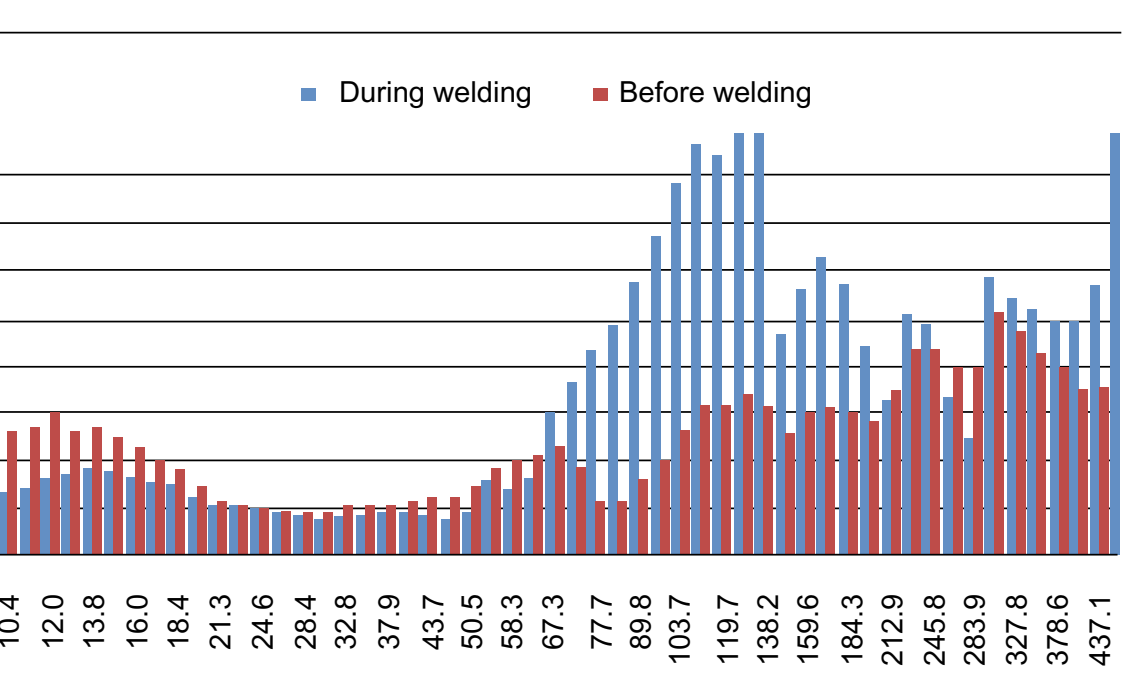

$\mathrm{Dp}(\mathrm{nm})$

Figure 10 (Continued) 


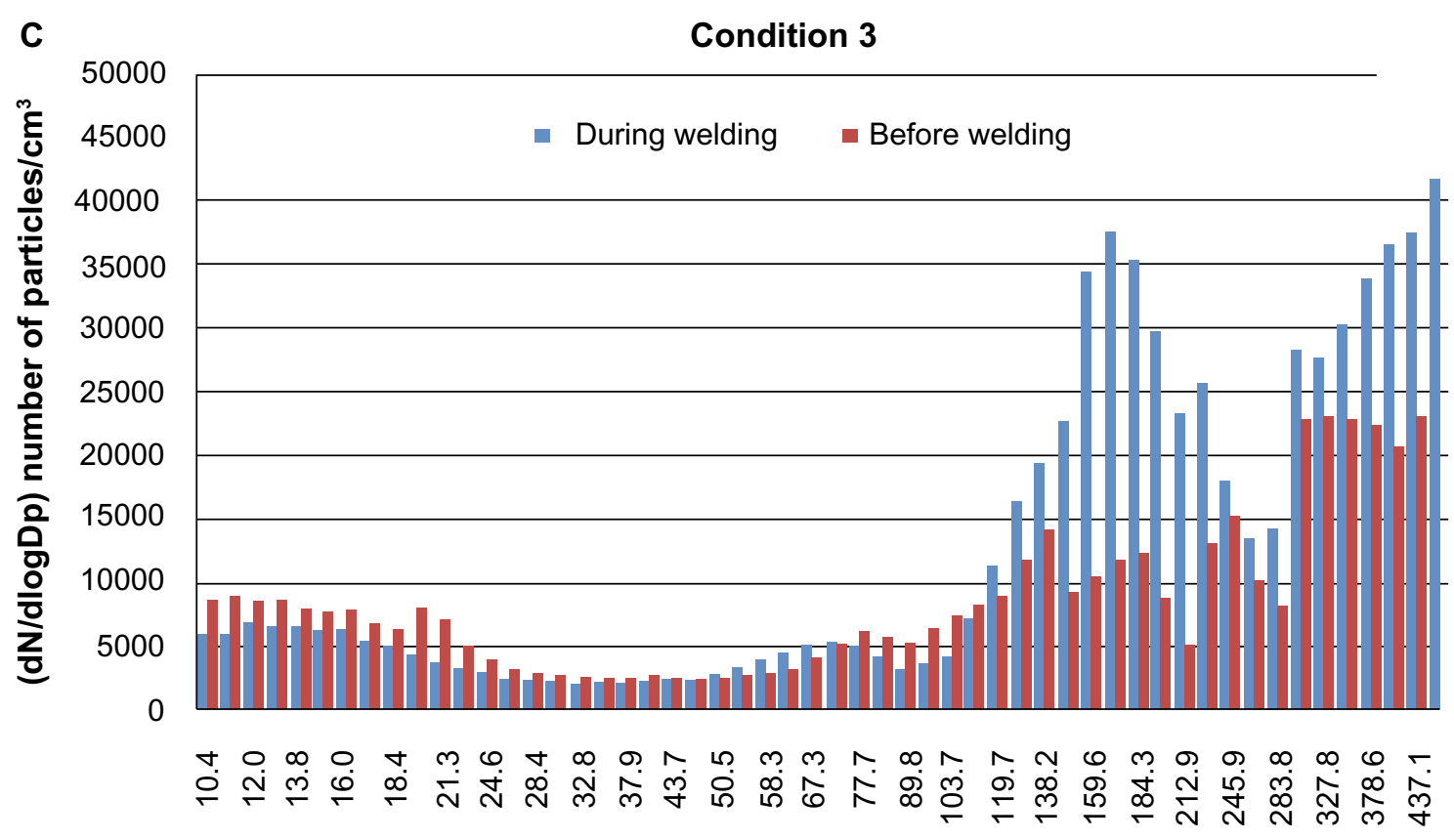

\section{Dp (nm)}

Figure 10 (A) Size distribution curves of emitted particulate for experimental condition I: metal active gas (MAG) welding, globular transfer with a gas mixture of Ar+ I8\% $\mathrm{CO}_{2}$. (B) Size distribution curves of emitted particulate for experimental condition 2: MAG welding, globular transfer with a gas mixture of Ar+8\% $\mathrm{CO}_{2}$. (C) Size distribution curves of emitted particulate for experimental condition 3: MAG welding, spray transfer with a gas mixture of $\mathrm{Ar}+18 \% \mathrm{CO}_{2}$.

Abbreviation: Dp, electrical mobility diameter.
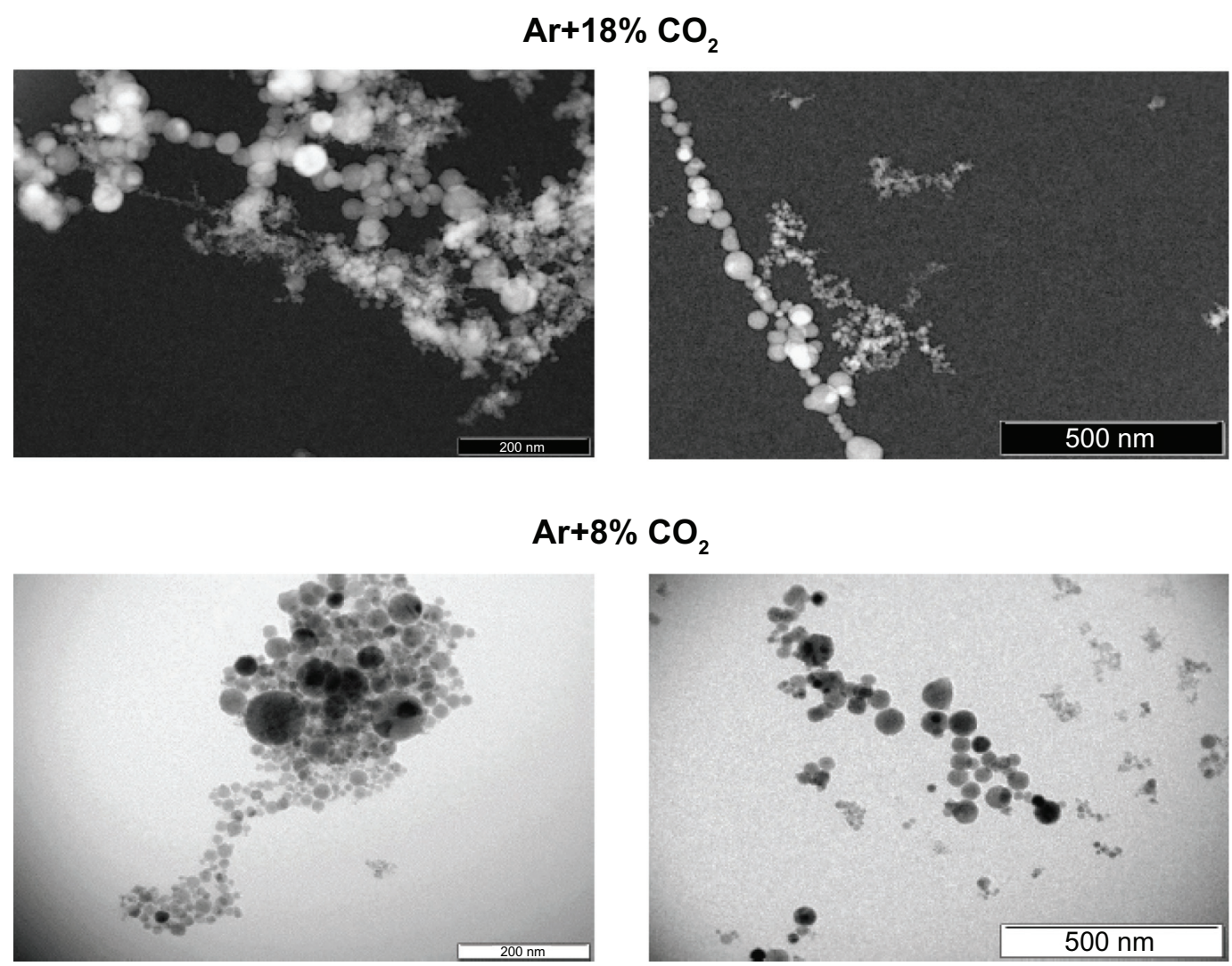

Figure II Transmission electron microscopy images of collected ultrafine particulate during metal active gas welding using gas mixture Ar+l8\% $\mathrm{CO}$ (top) and $\mathrm{Ar}+8 \% \mathrm{CO}_{2}$ (bottom). 

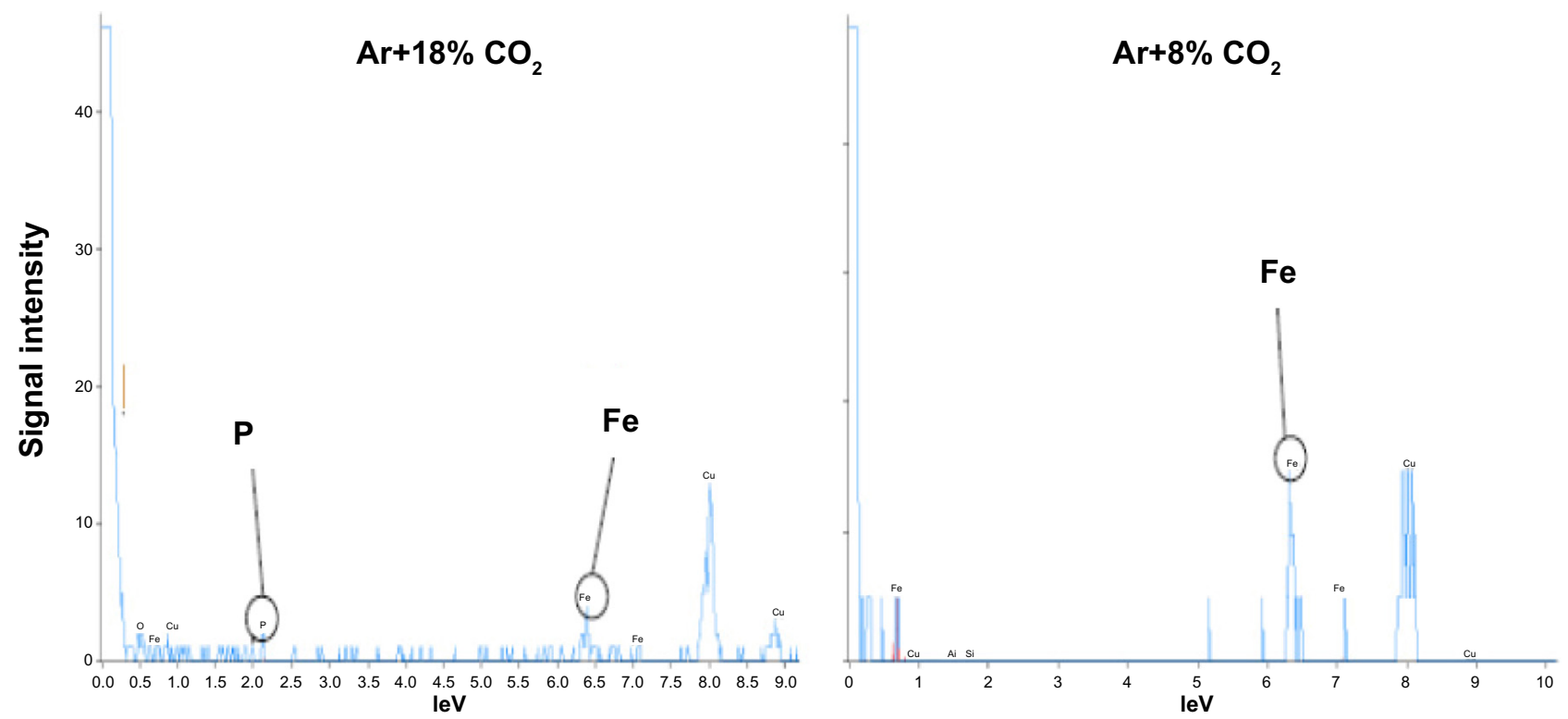

Figure 12 Chemical composition of collected ultrafine particulate during metal active gas welding using gas mixtures $\mathrm{Ar}+\mathrm{I} 8 \% \mathrm{CO}$ (left) and $\mathrm{Ar}+8 \% \mathrm{CO}$ (right). Abbreviation: leV, peak position (electron volt).

indicate contamination of potentially hazardous aerosols released from cooking activities.

Also, it should be noted that if exposure, as determined by this study, is quite high during domestic activities, prolonged exposure to more intense activities that occur during a work shift in restaurants and other cooking preparation establishments can be quite health damaging, without appropriate individual protection measures being taken, and thus warrants further studies and investigations.

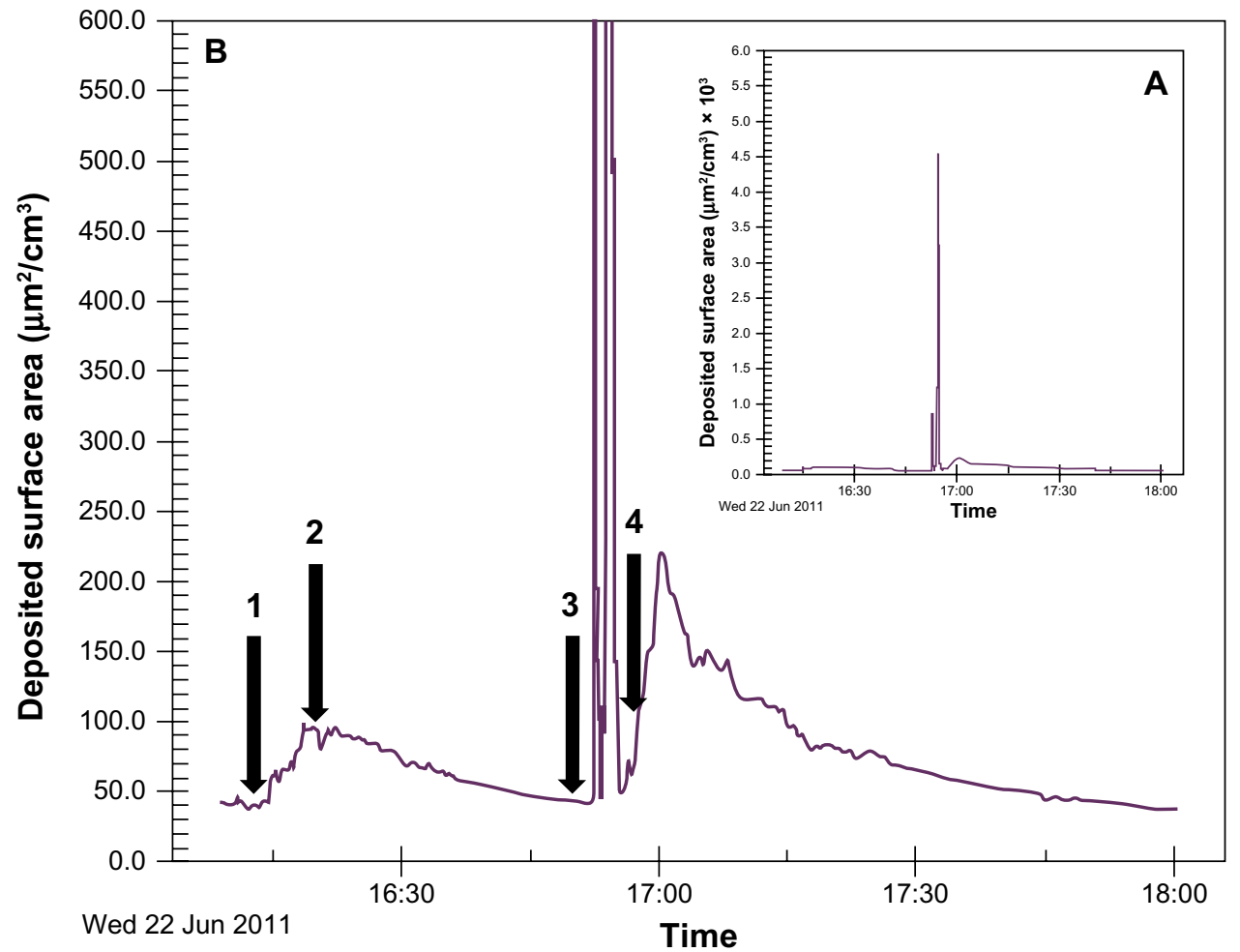

Figure 13 Measurements during hamburger and egg frying with cooking events (I: hamburger starts to fry; 2: hamburger cooked; 3: heat is turned on; 4: egg is removed) marked: (A) expanded scale $0.0-6,000 \mu \mathrm{m}^{2} / \mathrm{cm}^{3}$ and (B) reduced scale: $0.0-600 \mu \mathrm{m}^{2} / \mathrm{cm}^{3}$, showing the evolution of alveolar-deposited surface area with time. 


\section{Conclusion}

This methodology seems to be effective for monitoring UFPs in the mentioned environments (indoor or even outdoor) as well in other similar situations. The use of this equipment and experimental procedures provide very useful information for assessment of exposure as well as for risk assessment. The obtained information can be easily related to specific process conditions and physical constraints as well. Also, it helps in the determination of the real origin of the airborne UFPs, and in the definition of appropriate containment measures for emitted nanoparticles and good operational practices in order to reduce occupational exposure.

Regarding the assessment of exposure to nanoparticles, previous studies ${ }^{11}$ showed that instruments such as NSAMs are designed to measure airborne surface area concentrations that would deposit in the alveolar or TB region of the lung. It was found that this instrument can be reliably used for the size range of nanoparticles between $20 \mathrm{~nm}$ and $100 \mathrm{~nm}$, and also that the upper size range can be extended to $400 \mathrm{~nm}$, where the minimum in the deposition curve occurs. ${ }^{31}$ In fact, the size fraction below $20 \mathrm{~nm}$ usually contributes only negligibly to the total surface area and is therefore not critical. At the other end, for particles above $400 \mathrm{~nm}$, a preseparator is needed to remove those particles. Particle material does not seem to have a noticeable impact either on particle charging in NSAM or on the deposition curves within the aforementioned size range, but particle hygroscopicity can cause the lung deposition curves to change somewhat, which cannot be mimicked by the instrument. It was also found that the tendencies of the particle deposition curves of a reference worker for alveolar, TB, total, and nasal depositions share the same tendencies in the 20-400 nm size range and that their ratios are almost constant. By means of appropriate calibration factors, an NSAM can be used to deliver the lung-deposited surface area concentrations in all these regions, based on a single measurement. ${ }^{32}$ Therefore, NSAM equipment can be reliably used to supply information on the deposited surface area of UFPs.

Also, it has been noticed that an important information gap, which limits the use of data for epidemiological studies and quantitative risk assessment evaluations, is the absence of quantitative exposure data from which to estimate the dose-response relationship,,$^{33}$ which is particularly true when referring to UFPs. Envisaged future work will be related to the precise quantification of errors associated with the use of this methodology.

\section{Disclosure}

The authors report no conflicts of interest in this work.

\section{References}

1. Jenkins N, Eager T. Chemical analysis of welding fume particles. Welding Research. 2005;Supp 1:87-93.

2. Card J, Zeldin D, Bonner J, Nestmann E. Pulmonary applications and toxicity of engineered nanoparticles. Am J Physiol Lung Cell Mol Physiol. 2008;295:L400-L411.

3. Oberdörster G, Gelein R, Ferin J, Weiss B. Association of particulate air pollution and acute mortality: involvement of ultrafine particles. Inhal Toxicol. 1995;7:111-124.

4. Tsai C, Pui D. Editorial. J Nanopart Res. 2009;11:1-4.

5. Tsai C, Huang C, Chen S, et al. Exposure assessment of nano-sized and respirable particles at different workplaces. J Nanopart Res. 2011;13: 4161-4172.

6. Kreyling W, Semmler M, Erbe F, et al. Translocation of ultrafine insoluble iridium particles from lung epithelium to extrapulmonary organs is size dependent but very low. $J$ Toxicol Environ Health A. 2002;65:511-535

7. Oberdörster G. Significance of particle parameters in the evaluation of exposure-dose-response relationships of inhaled particles. Particulate Science and Technology. 1996;14:135-151.

8. Donaldson K, Li X, MacNee W. Ultrafine (nanometer) particle mediated lung injury. J Aerosol Sci. 1998;29:553-560.

9. Oberdörster G. Pulmonary effects of inhaled ultrafine particles. Int Arch Occup Environ Health. 2001;74:1-8.

10. Driscoll K. Role of inflammation in the development of rat lung tumors in response to chronic particle exposure. Inhal Toxicol. 1996;8: 85-98.

11. Fissan H, Neumann S, Trampe A, Pui D, Shin W. Rationale and principle of an instrument measuring lung deposited nanoparticle surface area. J Nanopart Res. 2007;9:53-59.

12. Phalen R. Particle size-selective sampling for particulate air contaminants. Vincent JH, editor. Cincinnati, OH: ACGIH; 1999.

13. Ostraat M, Thornburg J, Malloy Q. Measurement strategies of airborne nanomaterials. Environ Eng Sci. 2013;30:126-132.

14. Albuquerque P, Gomes J, Bordado J. Assessment of exposure to airborne ultrafine particles in the urban environment of Lisbon, Portugal. J Air Waste Manage Assoc. 2012;62:373-380.

15. Gomes J, Bordado J, Albuquerque P. Monitoring exposure to airborne ultrafine particles in Lisbon, Portugal. Inhal Toxicol. 2012;24: 425-433.

16. Bordado J, Gomes J, Albuquerque P. Exposure to airborne ultrafine particles from cooking in Portuguese homes. J Air Waste Manage Assoc. 2012;62:1170-1180.

17. Gomes J, Albuquerque P, Miranda R, Vieira M. Determination of airborne nanoparticles from welding operations. $J$ Toxicol Environ Health A. 2012;75:747-755.

18. Kuhlbusch T, Asbach C, Fissan H, Gohler D, Stinz M. Nanoparticle exposure at nanotechnology workplaces: a review. Part Fibre Toxicol. 2011;8:22.

19. Richman J, Livi K, Geyh A. A scanning transmission electron microscopy method for determination of manganese composition in welding fume as a function of primary particle size. J Aerosol Sci. 2011;42:408-418.

20. Kuhlbusch T, Qrum U, Koch M, Fissan H, Bruckman P, Pfeffer U. PM10 source apportionment at three urban background sites in the Wurten Ruhr area, Germany. J Aerosol Sci. 2004;35:79-90.

21. Ramachandran G, Paulsen D, Watts W, Kittelson D. Mass, surface area and number metrics in diesel occupational exposure assessment. J Environ Monit. 2005;7:728-735.

22. Gomez-Moreno F, Pujadas M, Plaza J, Rodriguez-Maroto J, Martinez-Lozano P, Artinano B. Influence of seasonal factors on the atmospheric particle number concentration and size distribution in Madrid. Atmos Environ. 2011;45:3169-3180.

23. Morawska L, Jayaratne E, Mengersen K, Jamiska M, Thomas S. Differences in airborne particle and gaseous concentrations in urban air between weekdays and weekends. Atmos Environ. 2002;36: 4375-4383. 
24. Pires I, Quintino L, Miranda RMM, Gomes JFP. Fume emissions during gas metal arc welding. Toxicol Environ Chem. 2006;88:385-394.

25. Berlinger B, Benker N, Weinbruch B, Ebert M, Ellingsen D, Thomassen Y. Physicochemical characterization of different welding aerosols. Anal Bioanal Chem. 2011;399:1773-1780.

26. Elihn K, Berg P, Liden G, Correlation between airborne particle concentrations in seven industrial plants and estimated respiratory tract deposition by number, mass and elemental composition. J Aerosol Sci. 2011;42:127-141.

27. Schauer M, Kleemna M, Cass G, Simoneit B. Measurement of emissions from air pollution sources 4. C1-C27 organic compounds. Environ Sci Technol. 2002;36:567-575.

28. Mohr C, DeCarlo P, Hering M, et al. Identification and quantification or organic aerosol from cooking and other sources in Barcelona using aerosol mass spectrometer data. Atmos Chem Phys Discuss. 2011;11: $27383-27420$.
29. Hildemann L, Markowski G, Jones M, Cass G. Submicrometer aerosol mass distributions of emissions from boilers, fireplaces, automobiles, diesel trucks and meat cooking operations. Aerosol Sci Technol. 1991;14:138-152.

30. Rogge W, Hildemann L, Mazurek M, Cass G, Simoneit B. Sources of fine organic aerosol. 5. Natural gas home appliances. Environ Sci Technol. 1993;27:2736-2744.

31. Asbach C, Fissan H, Stahlmecke B, Kuhlbusch T, Pui D. Conceptual limitations and extensions of lung-deposited nano particle surface area monitor (NSAM). J Nanopart Res. 2009;11:101-109.

32. Wilson W, Stanek J, Han H, et al. Use of electrical aerosol detector as an indicator of the surface area of fine particles deposited in the lung. J Air Waste Manage Assoc. 2007;57:211-220.

33. Mauderley J. Environmental toxicants: human exposures and their health effects. Lippman M, editor. New York: Van Nostrand Reinhold; 1992

\section{Publish your work in this journal}

Energy and Emission Control Technologies is an international, peer-reviewed, open access journal publishing original research, reviews, editorials and commentaries on developing technologies to optimize energy production and control of emissions. The manuscript management system is completely online and includes a very quick and fair peer-review system, which is all easy to use. Visit http://www.dovepress.com/testimonials.php to read real quotes from published authors.

Submit your manuscript here: http://www.dovepress.com/energy-and-emission-control-technologies-journal 